\title{
Dendritic cells in autoimmune disorders and cancer of the thyroid
}

\author{
Andrzej Lewinski, Przemyslaw Wiktor Sliwka, Mariusz Stasiolek \\ Department of Endocrinology and Metabolic Diseases, Polish Mother's Memorial Hospital \\ - Research Institute, Lodz, Poland
}

\begin{abstract}
Dendritic cells (DCs), considered as one of the crucial immune regulatory populations, are implicated in the immune pathology of various disorders. Also in the thyroid gland, DCs were shown to be involved in early and chronic phases of various types of autoimmunity - including Hashimoto's thyroiditis and Graves' disease. In thyroid malignant processes, DCs are suggested as an important element of both tumour defence and tumour immune evasion mechanisms. Recent findings emphasize a crucial role of interactions between particular DC subsets and other regulatory cell populations (e.g. FoxP $3^{+}$regulatory T cells) in thyroid pathology. Additionally, an increasing attention has been paid to the control of DC function by thyrometabolic conditions. (Folia Histochemica et Cytobiologica 2014, Vol. 52, No. 1, 18-28)
\end{abstract}

Key words: dendritic cells; thyroid; thyroid cancer; Hashimoto's thyroiditis; Graves' disease; Treg cells; thyroid hormones; TSH

\author{
Abbreviations: \\ AITD - autoimmune thyroid disease \\ APCs - antigen presenting cells \\ cDCs - conventional dendritic cells \\ DCs - dendritic cells \\ EAT - experimental autoimmune thyroiditis \\ FasL - Fas ligand \\ Flt 3 - fms-like tyrosine kinase receptor 3 ligand \\ FNAB - fine needle aspiration biopsy \\ GD - Graves' disease \\ GM-CSF - granulocyte-macrophage colony-stimu- \\ lating factor \\ HT - Hashimoto's thyroiditis \\ IDO - indoleamine 2,3-dioxygenase \\ IFN - interferon \\ IL — interleukin \\ ILT3 - immunoglobulin like transcript 3 \\ LAMP - lysosomal associated membrane protein \\ Corresponding author: A. Lewinski M.D., Ph.D., \\ Department of Endocrinology and Metabolic Diseases, Polish \\ Mother's Memorial Hospital - Research Institute, \\ 281/289 Rzgowska St., 93-338 Lodz, Poland; \\ tel.: +48 4227111 41; fax: +48 4227111 40; \\ e-mail: alewin@csk.umed.lodz.pl
}

LPS — lipopolysaccharide

LT4 - levothyroxine

MHC - major histocompatibility complex

MTC - medullary thyroid carcinoma

$\mathrm{MxA}$ - myxovirus resistance protein A

$\mathrm{NF}$ - nuclear factor

PBMC - peripheral blood mononuclear cells

pDCs - plasmacytoid dendritic cells

PSGL-1 - P-selectin glycosylated ligand 1

PTC — papillary thyroid carcinoma

$\mathrm{T} 3$ - triiodothyronine

TFCs - thyroid follicle cells

$\mathrm{Tg}$ - thyroglobulin

TGF $-\beta 1$-transforming growth factor beta 1

Th - T helper (cell)

$\mathrm{TNF}$ - tumour necrosis factor

Tregs - regulatory $\mathrm{T}$ cells

TRs - thyroid hormone receptors

$\mathrm{TSH}$ - thyroid stimulating hormone

\section{Introduction}

Dendritic cells (DCs) are considered to represent a population of the most potent antigen presenting cells (APCs). Immature DCs, spread throughout virtually all body compartments, are able to capture 


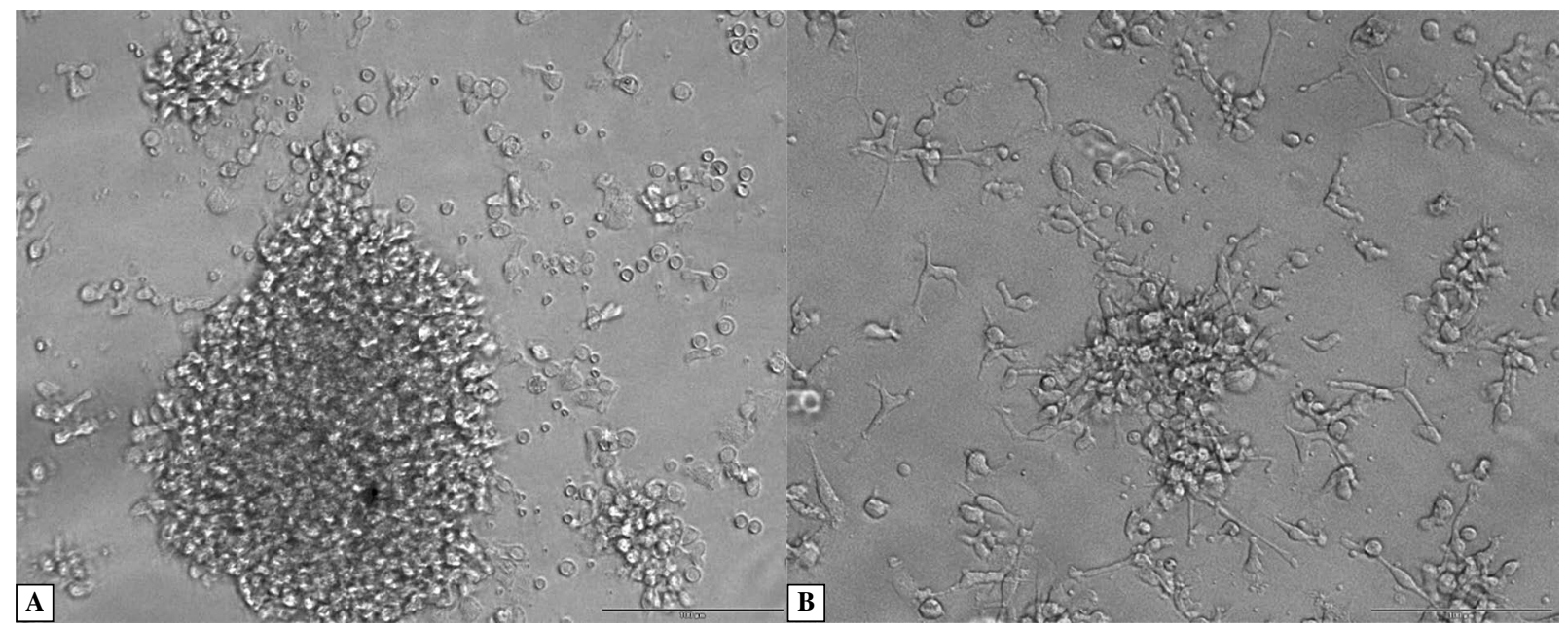

Figure 1. Human peripheral blood plasmacytoid (p)DCs matured in vitro. pDCs were sorted magnetically from leukapheresis preparation obtained from healthy volunteer. Isolated pDCs (purity of CD303+CD123+ pDC fraction $>95 \%$, as assessed by flow cytometry) were cultured for $96 \mathrm{~h}$ on 48 -well culture plates in culture medium supplemented with recombinant human IL-3 and recombinant human soluble CD40 ligand (living cells assessed by light microscopy; scale bar $=100 \mu \mathrm{m}$ ). (A) $24 \mathrm{~h}$ of culture - immature pDC form predominantly large clusters of cells. (B) $96 \mathrm{~h}$ of culture $-\mathrm{pDCs}$ disperse from clusters, majority of pDCs acquired "dendritic" morphology

and process antigens in order to present them in the context of appropriate major histocompatibility complex (MHC) molecules [1]. Antigen encounter stimulates a process of DC maturation associated with profound alterations of phenotypic and functional properties [2]. Sequential changes in the repertoire of chemokine and pattern recognition receptors regulate DC migratory activity [3], whereas the parallel enhancement of costimulatory molecules expression prepares activated DC for an optimal interaction with effector cells [2]. Among the known costimulatory molecules the most important for DC function belong to $\mathrm{B} 7$ (e.g. CD80, CD86, B7-H1) $[4,5]$ and tumour necrosis factor (TNF)/TNF-receptor superfamilies (e.g. CD40, lymphotoxin- $\beta$ receptor, OX40 ligand, $4-1 \mathrm{BB}$ ligand) [6]. However, multiple other DC costimulatory systems have been lately described including Serrate-like molecules (Jagged-1 and Jagged-2) which upon interaction with Notch receptor on T cells take part in regulatory $\mathrm{T}$ cell (Tregs) generation $[7,8]$. The DC maturation process encompasses also substantial changes in secretion profile of cytokines, chemokines and other humoral factors [2], as well as modification of activity of enzymes crucially involved in immune system function like indoleamine 2,3-dioxygenase (IDO) [9]. The phenotypic and functional changes undergoing during DC maturation depend strongly on the quality and quantity of processed antigens, and the microenvironmental factors including other immune and non-immune cells, which influence de- eply the direction, intensity, course and outcome of the initiated immune reaction [10].

Dendritic cells are known as heterogeneous group of APCs. Two main lineage backgrounds - plasmacytoid (pDCs) and myeloid or conventional (cDCs), provide cells with distinct functional properties and crucial engagement both in innate and adaptive immune system. These two main subsets differ in surface molecule expression, cytokine secretion profile, efficacy of antigen uptake and presentation [11]. The conventional myeloid DC subset is believed to promote typically $\mathrm{T}$ helper (Th) 1 and Th17 immune response in mechanism involving secretion of high amounts of IL-12 and IL-23 [12, 13]. To the contrary, pDCs are known as one of the main sources of type I interferons (IFN I) and were suggested in various experimental settings as crucial for Th2 and regulatory $T$ cells generation and function [14-17]. Figure 1 presents morphological changes of human peripheral blood pDCs matured in culture.

The involvement of DCs in immune tolerance induction and maintenance encompasses both central and peripheral mechanisms [11]. In the thymus, DCs play a key role in the process of negative selection in which they present self-antigens to the developing thymocytes in order to detect and delete autoreactive cells [18]. In the periphery, DCs take part in the control of differentiation, expansion and activity of various regulatory cell populations including inducible Tregs [19-21]. 


\section{Dendritic cells in normal thyroid}

DCs represent an important element of peripheral organ immune surveillance. However, the exact characterization of tissue specific DC populations confers significant methodological problem due to the very low numbers of these cells in particular tissues. The prevalence of DCs in pig thyroid gland (analysed on the basis of cell adhesive properties and surface expression of MHC class II, mannose receptor and S-100 - a molecule considered as a nonspecific marker of both mature and immature DCs [22]) was estimated as $2-3 \%$ of total cellular components of the thyroid. In culture, most of these thyroid derived DCs presented marked endocytic capacity, suggestive of initial maturation stages [23]. Early studies of antigen presenting cells in human thyroid gland found a little amount of DCs, recognized as cells with characteristic nucleus shape, long cytoplasmic protrusions and MHC class II membrane molecules. Those cells were localized outside thyroid follicles [24]. However, the characteristics of the local thyroid DC populations seem to be substantially affected by various pathological processes of the thyroid. In iodine deficient goitre number of DCs, epithelioid cells, and multinucleated giant cells was higher than in the healthy thyroid gland. DCs were seen in interstitium clustered in focal aggregates [25, 26].

\section{Dendritic cells in thyroid autoimmune diseases}

The first evidences of the role of DCs in pathogenesis of the thyroid autoaggression were demonstrated in $\mathrm{BB} / \mathrm{O}$ rat - an animal model of spontaneously developing autoimmune disease of the thyroid [27, 28]. Even in the initial stages of the disease infiltrating DCs were present in thyroid, followed by large accumulation of DCs, as well as B and T cells beginning from the 18th week of age [28]. DCs were also shown in thyroid infiltrates early in the course of iodine-induced thyroiditis in autoimmune prone non-obese diabetic mice [29]. The involvement of DCs in thyroid immunopathology was further confirmed in various forms of the experimental autoimmune thyroiditis (EAT). Transfer of syngeneic splenic DCs pulsed in vitro with thyroglobulin $(\mathrm{Tg})$ or necrotic thyrocytes to healthy animals resulted in a development of EAT [30-32]. Similarly, DCs isolated from animals with EAT induced by active Tg immunization, were able - upon adoptive transfer - to initiate thyroid immune reaction in healthy animals [30]. However, the role of DCs in EAT induction and development was shown to be much more complicated. In vitro or in vivo modulation of $\mathrm{DC}$ differentiation, maturation and activation, depending on the time of intervention, could significantly influence the induction and the clinical course of active form of EAT [33, 34]. Different modes of immune manipulation (e.g. fms-like tyrosine kinase receptor 3 ligand, Flt3L vs. granulocyte-macrophage colony-stimulating factor, GM-CSF) affecting differentiation, bone marrow mobilization, proliferation and survival of particular DC subsets could lead to opposite clinical effects with $\mathrm{CD} 11 \mathrm{c}^{+} \mathrm{CD} 8 \mathrm{a}^{-} \mathrm{DCs}$ suggested as crucial players in EAT amelioration, as confirmed in an adoptive transfer study $[34,35]$. On the other hand, the EAT inhibitory effects in experimental models implementing various methods of DCs functional modulation (such as TNF- $\alpha$ incubation ex vivo or GM-CSF administration ex vivo and in vivo) seem to be mediated by similar mechanisms associated with DC dependent expansion of $\mathrm{CD}^{+}{ }^{+} \mathrm{CD} 25^{+} \mathrm{FoxP}^{+}{ }^{+}$Tregs secreting high amounts of IL-10 [33-36]. CD $4{ }^{+} \mathrm{CD} 25^{+} \mathrm{FoxP} 3^{+}$ Tregs play a crucial role in the control of peripheral immune homeostasis and tolerance maintenance. Due to their potent immunoregulatory properties Tregs, generated both in thymus (natural Tregs) and in periphery (inducible or adaptive Tregs), are considered as efficient regulators of various immune processes including autoaggressive and allergic reactions as well as response to tumour cells and different infectious factors [11, 37, 38].

Further studies showed that GM-CSF affected murine DCs regulatory properties already at the level of DC differentiation from bone marrow precursors resulting in a CD $11 \mathrm{c}^{+} \mathrm{CD} 8 \mathrm{a}^{-} \mathrm{DC}$ population secreting high amounts of TGF- $\beta$ and able to expand $\mathrm{CD}^{+}{ }^{+} \mathrm{CD} 25^{+} \mathrm{FoxP}^{+}$Tregs in vitro $[8,39]$. The DC - Tregs interaction was contact dependent and involved interaction of OX40L and Jagged 1 molecules (expressed on DC surface) with their receptors on Tregs (OX40 and Notch3, respectively) [8,39]. Accordingly, only the $\mathrm{OX} 40 \mathrm{~L}^{+} \mathrm{Jagged}^{+} \mathrm{DCs}$, upon adoptive transfer to EAT animals, were able to expand Tregs and suppress the clinical symptoms of the disease [8].

Surprisingly, there are relatively few studies available regarding the role of DCs in human autoimmune thyroid disease (AITD). Several studies have shown, that population of DCs was increased in thyroid infiltrating cells in both main AITD forms - Hashimoto's thyroiditis (HT) and Graves' disease (GD). Compared with toxic and non-toxic goitre, the number of infiltrating DC was increased in GD. Immature DC were selectively found perifollicularly, while partially matured DC were seen in connective tissue and focal interstitial clusters [40]. Another analysis of cellular components of thyroid tissue from GD and HT sub- 
jects showed that mature $\mathrm{CD} 83^{+} \mathrm{DC}$ were present in the infiltrates scattered outside thyroid follicles or in the periphery of lymphoid follicles. Further characterization with fluorescence microscopy demonstrated also expression of CD1 molecules (CD1a, CD1b, and CD1c) on the surface of thyroid DCs [41]. Higher proportion of S-100 and CD83 positive DCs was also found in HT and GD thyroid specimens, as compared with follicular thyroid adenoma [42]. An analysis of gene expression pattern in GD thyroid tissue using a gene chip system revealed disease stage dependent (short vs. long course GD) regulation of many genes associated with immune system including induction of lineage specific antigens of T- and B-cells, macrophages, as well as DCs in long course GD. Immunofluorescence analysis of thyroid specimens confirmed the presence of $\mathrm{CD} 303^{+} \mathrm{CD} 123^{+} \mathrm{CD} 83^{-}$immature pDCs typically in close contact with lymphocytes, as well as CD11c ${ }^{+}$cDCs, which were also identified as a potential local source of IFN $\alpha$ [43]. Disease stage dependent changes in the structure of thyroid immune infiltrates was also shown by Hammerstad and colleagues in immunostaining assays of thyroid tissue obtained both from HT [44] and GD patients [45]. In the newly diagnosed untreated GD patients, the authors observed a significant increase of thyroid pDC population, as compared with chronic GD and healthy subjects. Importantly, the number of pDCs correlated with the expression of interferon-inducible Myxovirus Resistance Protein A (MxA) regarded as a marker of IFN I production [45]. Similar increase in thyroid pDCs population and MxA expression was observed in HT patients. However, in contrast to GD, these parameters did not depend on HT clinical stage [44], whereas in both AITD forms the later phases of the disease were associated with local accumulation of $\mathrm{CD}^{+} \mathrm{T}$ cells $[44,45]$. Interestingly, also in a study analysing peripheral blood DCs in AITD pDC (but not the whole DC) population was significantly increased in untreated hyperthyroid GD patients as compared with healthy subjects, euthyroid GD and euthyroid HT patients. Moreover, the expression of CD80, CD86, and CD40 was slightly increased in untreated GD patients, comparing with healthy subjects [46]. The pDC/DC ratio was considerably higher in untreated GD (as juxtaposed to other AITD patients) and correlated negatively with the count of $\mathrm{CD}^{+}{ }^{+} \mathrm{CD} 25^{+} \mathrm{FOXP} 3{ }^{+}$population of peripheral blood Tregs. Furthermore, pDCs obtained from untreated GD patients revealed significant ability to suppress inhibitory action of regulatory $\mathrm{T}$ cells and in this way promoted the proliferation of effector $\mathrm{T}$ cells in co-cultures. Importantly, such pronounced Tregs-inhibitory activity was not observed with none of the $\mathrm{cDC}$ populations nor with $\mathrm{pDC}$ derived from euthyroid patients [46].

In the recently published study, Leskela and colleagues performed for the first time a complex analysis of DC subpopulations parallel in the thyroid gland and peripheral blood of patients with different forms of AITD [47]. The peripheral blood pDC population was significantly lower in both HT and GD patients than in healthy controls and such difference was not observed in cDC population. The phenotypic analysis revealed additionally differences in DC specific expression of lymphocyte inhibitory molecules (immunoglobulin like-transcripts - ILT3 and P-selectin glycosylated ligand - PSGL-1) [47]. In HT patients, peripheral blood pDCs showed significantly lower level of ILT3 expression, whereas in GD peripheral blood pDCs were characterized by decreased expression of PSGL-1. Moreover, the percentage of peripheral blood pDCs positive for CD69 activation marker was negatively correlated with disease progression in GD patients. The percentage of pDCs was significantly higher in thyroid tissue than in peripheral blood of the same AITD patients - both in GD and HT. However, thyroid derived pDCs obtained from HT and GD patients expressed lower levels of ILT3 and PSGL-1 than peripheral blood pDCs [47]. In order to better characterize possible pDC specific functional abnormalities the authors analysed the expression of IDO - enzyme involved in tryptophan metabolism, with well-known potent immunoregulatory activities [48]. The abnormalities of DC specific IDO expression have been shown earlier to participate in the pathogenesis of organ specific autoimmune reactions [49]. Accordingly, in HT patients significantly lower percentage of peripheral blood pDCs expressed IDO as compared with healthy subjects, which was paralleled by abnormal serum tryptophan/ /kynurenine ratios in those patients. Furthermore, HT derived $\mathrm{pDC}$ showed increased IFN- $\alpha$ production in response to TLR7/9 stimulation in vitro [47]. Another study comparing the properties of local thyroid and peripheral blood DCs showed that in AITD patients intrathyroidal CD4 ${ }^{+} \mathrm{T}$ lymphocytes revealed higher expression of Fas compared with those in blood and intrathyroidal DCs showed higher expression of Fas ligand (FasL) than peripheral blood DCs. Since Fas molecule - member of TNF/TNF-receptor superfamily - is regarded as one of the main cell-death signal transducers, this observation may be of potential importance for local control of lymphocyte activation and apoptosis and, thus, may represent a sign of the ongoing disease suppressing processes [50]. Fas ligation by FasL present on DCs and thyrocytes may induce caspase 8 dependent apoptosis pathway 
in Fas-expressing immune cells and thus serve as one of the peripheral tolerance mechanisms in the thyroid [50]. Significantly higher expression of Fas and FasL was also presented by flow cytometry in the thyroid follicle cells (TFCs) obtained from AITD patients as compared with non-toxic nodular goitre controls. Interestingly, the TFCs specific expression of Fas and FasL was significantly higher in HT than GD patients, whereas the intrathyroid lymphocytes expressed higher levels of these proapoptotic molecules in GD than in HT [51]. The higher expression of Fas and FasL molecules in HT than GD derived thyrocytes was confirmed also by $\mathrm{Xu}$ and co-workers, and correlated additionally with the differences in the expression of $\mathrm{Bcl}-2$ apoptosis-related protein which was strongly expressed by GD thyrocytes but not in HT thyroid cells [42]. Altogether, these data suggest a substantial, disease specific role of particular DC subsets - especially pDCs - in the control of various phases of thyroid autoimmune processes.

\section{Thyroid cancer}

It has been suggested that chronic inflammation characterized by sustained tissue damage followed by damage-induced repair may lead to atypical cell production and proliferation, as well as to accumulation of highly mutagenic agents which may in turn contribute to the carcinogenesis [52]. Accordingly, chronic immune processes were widely investigated as important elements of tumourigenesis of many origins [53-55], including the possible connection of thyroid malignancies with HT associated thyroid microenvironment - rich of immune cells producing large amounts of humoral mediators, such as cytokines, growth factors and oxygen and nitrogen reactive species $[52,56]$. The coexistence of papillary thyroid carcinoma (PTC) and HT was a subject of many studies which investigated the causative linkage between this two thyroid pathologies [57-61]. However, the recently published review showed high discrepancy of the results and revealed many conflicting reports on the correlation of PTC and HT [62]. The prevalence rate of PTC in HT patients was estimated in different studies from $0 \%$ to $36.6 \%$ and the results seemed to be strongly dependent on the research methodology. Studies based on the material obtained from fine needle aspiration biopsy (FNAB) revealed low (average $1,20 \%$ ) prevalence and also low relative risk ratio of PTC in HT. To the contrary, studies analysing archival thyroidectomy specimens reported a statistically significant correlation between PTC and HT with higher prevalence (average $27.56 \%$ ) and higher risk ratio of PTC in HT patients [62]. Additionally, some of the molecular and genetic markers of thyroid malignancy were found in the immune infiltrates surrounding tumour cells and/or in chronic thyroiditis specimens (including RET/PTC gene recombination present in multiple investigated HT cases) [63, 64]. In the study performed in our department, however, $\mathrm{Cy}-$ niak-Magierska and co-workers did not found RET/ /PTC1 or RET/PTC3 rearrangements in patients with HT [61]. Moreover, in RET/PTC transgenic animals thyroid tissue was characterized by significantly higher production of inflammatory mediators [65]. These observations support the possible engagement of chronic inflammation molecular mechanisms in the tumourigenesis induction. However, immune system plays a substantial role also in later stages of tumour development. A modulation of the host defence into immune settings, supporting or not cancer cell survival, is assumed as one of the most important conditions governing the extend of tumour growth and spreading [66, 67]. Numerous tumour specific and tissue damage associated humoral factors attract immune cells and modulate their functional properties [68-71]. The tumour infiltrating immune cells could serve for example as an important source of angiogenetic factors [72-74]. Additionally, the local tumour specific microenvironment may lead to the induction of dominant tolerance mechanisms and in consequence to tumour immune escape. An expansion of various regulatory cell populations such as DCs $[72,75,76]$, Tregs $[67,74,77,78]$ or myeloid-derived suppressor cells $[67,79,80]$ plays most probably a crucial role in this process. In thyroid carcinoma the process of infiltration with particular immune cell populations, including tumour associated monocytes, myeloid-derived suppressor cells, FoxP $3^{+}$Tregs, and other lymphocytic subsets, was correlated with tumour type and level of aggressiveness [67, 81-83]. Also, the role of DCs mediated immunoregulatory processes was postulated in the development of thyroid malignancies. Already the first studies showed significant differences in the intensity of S- $100^{+}$DCs infiltration in particular types of thyroid carcinoma with PTC specimens characterized by the highest DCs density $[84,85]$. Such observation was confirmed in further analyses, demonstrating significantly higher accumulation of S- $100^{+}$DCs or CD1 a immature DCs in PTC as compared with follicular carcinomas [68, 86, 87], medullary carcinomas [69] and poorly differentiated and undifferentiated carcinomas [87, 88], as well as adenomas [86, 89-91] and benign thyroid nodules [92]. The abundant DCs infiltration in PTC was observed in all tumour histotypes including diffuse sclerosing variant $[86,88,93,94]$. A specific distribution of infiltrating DCs was demonstrated in various tumours, 
where immature CD1a ${ }^{+}$DCs of Langerhans cell-type (expressing Langerin - a member of $\mathrm{Ca}^{2+}$-dependent (C-type) lectin family, associated with the structure of Birbeck granules - uniquely formatted cytoplasmic organelle of Langerhans cell [95]) tended to reside within the tumour, while mature DCs were mostly found in peritumoural areas [96-98]. Similarly, DCs infiltrating PTC nodules were shown to represent mainly immature $\mathrm{CD}^{2} \mathrm{a}^{+}$phenotype $[69,86,88,92]$. Mature $\mathrm{CD} 83^{+} \mathrm{DC}$ were described predominantly outside carcinoma nodules [89, 90]. However, DCs expressing another maturation marker - Lysosomal-Associated Membrane Protein (LAMP) were found also in the intratumoural area $[86,91]$. Most importantly, the study comparing DC infiltration in follicular variant of PTC and thyroid adenomas, revealed significantly increased numbers of $\mathrm{CD} \mathrm{a}^{+}$ immature DCs in PTC, whereas mature $\mathrm{LAMP}^{+}$DCs accumulated to similar extent in malignant and benign thyroid tumours [91].

The clear association of tumour infiltrating DCs with PTC, as compared with more aggressive carcinomas of the thyroid, led to an assumption that the extend of DC accumulation in PTC could correlate positively with favourable clinical course $[84,87]$. The recently published study analysing retrospectively thyroid specimens of 69 classical-type PTC patients revealed that $\mathrm{S}-100^{+} \mathrm{DC}$ density, both in the tumoural tissue and areas of concomitant thyroiditis, was associated with the intensity of lymphocytic thyroiditis. Moreover, short-term disease-free survival correlated positively with the thyroiditis grade but not with the number of infiltrating DCs [99]. This observation seems to be very interesting in the light of earlier reports, showing distinctive for PTC phenotypes of infiltrating DCs including expression pattern of chemokines receptors and adhesion molecules $[68,86]$, as well as low expression of costimulatory molecules such as CD86 [69, 89, 90]. These data suggest that DCs recruited to thyroid lesions in PTC instead of exerting defensive actions may be engaged in tumour immune escape processes. Unfortunately, the knowledge of the interaction between DCs and other immune regulatory cell populations in thyroid malignancies remains scarce. In the newly published study, Yu and co-workers demonstrated expansion of FoxP $3^{+}$Tregs in peripheral blood and thyroid tissue of patients with multinodular goitre coexisting with PTC as compared with multinodular goitre cases without malignancy [100]. The subpopulation of FoxP3 ${ }^{+}$Tregs expressing Inducible $\mathrm{T}$ cell Costimulator (ICOS, costimulatory molecule belonging to B7 superfamily) was shown to be a strong predictor of progression in metastatic PTC cases. Interestingly, in thyroid tissue of PTC patients the number of $\mathrm{FoxP}^{+} \mathrm{ICOS}^{+}$Tregs correlated positively with pDCs suggesting an engagement of PTC infiltrating pDCs in expansion of other regulatory cells and in consequence in tumour immune evasion [100].

The postulated engagement of DCs in the immune control of thyroid malignancies formed a basis for the application of DCs in experimental immune therapies - mainly in medullary thyroid carcinoma (MTC). In Ret/Cal mice (regarded as an animal model of MTC) vaccination with amino acid-modified calcitonin-pulsed DCs resulted in diminished tumour outgrowth [101]. Few cases of partial disease stabilization were also observed in several small series of medullary thyroid carcinoma studies and in a single study with PTC and follicular carcinoma patients vaccinated with autologous DCs preincubated with tumour lysates [102-106]. However, taking in consideration rather mediocre clinical benefits, further research is needed to enhance the anti-tumour activity of DC-based anti -tumour vaccines in thyroid carcinomas.

\section{Dendritic cells and thyroid-pituitary axis}

The expression of thyroid hormone receptors (TRs) was found in both immature and mature murine bone marrow-derived DCs - the $\beta_{1}$ isoform of TR $\left(\operatorname{TR} \beta_{1}\right)$ was highly expressed in cDCs and preferentially localized in cytoplasm. It was shown that physiological levels of triiodothyronine (T3) induced DC maturation and surface expression of HLA-DR, CD80, CD86 and CD40 in vitro. Moreover, IL-12 production in T3 stimulated DCs was markedly increased, with no effect on IL-10 secretion. T3 potentiated also the ability of bone marrow derived DCs to induce naive $\mathrm{T}$ cell proliferation and IFN- $\gamma$ production in allogeneic cocultures. Importantly, in this experimental model, DC phenotype changes associated with T3 stimulation were similar to those induced by lipopolysaccharide (LPS), the potent DC activation and maturation factor [107]. Additionally, dexamethasone a glucocorticosteroid, known as a suppressor of LPS induced DC maturation, inhibited in vitro the effects exerted by $\mathrm{T} 3$ on murine bone marrow DCs including changes in costimulatory phenotype and secretion profile, as well as their immunoregulatory function [108]. Further analysis of molecular mechanisms underlying the effects of thyroid hormones on murine bone marrow-derived DC suggested an activation of signal transduction pathways associated with Akt and Nuclear Factor (NF)- $\kappa$ B. Increased Ser-473 phosphorylation of Akt was shown to be specific for T3 dependent DC maturation, whereas NF- $\kappa \mathrm{B}$ activation was presented as an important element of both T3and LPS-associated intracellular signalling pathways. 
On the contrary, $\mathrm{T} 3$ dependent maturation processes in murine bone marrow DCs did not involve activation of extracellular signal-regulated kinase, protein kinase A, c-Jun N-terminal kinase and protein phosphatase $2 \mathrm{~A}$ signal transduction pathways. Importantly, the effects exerted by T3 on DCs in vitro were TR $\beta_{1}-$ binding dependent and encompassed regulation of $\operatorname{TR} \beta_{1}$ expression [109].

In the study performed in our laboratory, we investigated the influence of thyroid hormones on naturally occurring human peripheral blood DCs. In order to gain an insight into the in vivo regulatory processes associated with thyroid hormones in humans, we implemented an experimental model in which we assessed immune parameters in patients who underwent total thyroidectomy, i.e. patients lacking endogenous thyroid hormones production. The quantity and phenotype of cDCs and pDCs were analysed in two consecutive time points: before commencement of levothyroxine (LT4) supplementation (hypothyroidism) and after two months of sufficient LT4 administration (euthyroidism). Interestingly, in peripheral blood of LT4 treated patients we observed an increased proportion of $\mathrm{pDC}$ and $\mathrm{cDC}$ populations. The phenotypic analysis revealed increased level of HLA-DR surface expression in both main DC subsets. Moreover, the expression of CD86 on pDCs increased in euthyroidism, whereas this parameter remained stable in cDCs population. Expression of the other maturation markers (CD40, CD80 and CD83) did not change in the course of LT4 treatment in none of the investigated DC subsets [110]. In autologous coculture experiments, T3 enhanced the ability of freshly isolated human peripheral blood DCs to stimulate the proliferation and IL-12 production of peripheral blood mononuclear cells (PBMC) in response to mitogen (concanavalin A). Interestingly, in this autologous coculture system T3 showed additive action with signals mediated through soluble CD40 ligand (CD154) [110].

Because of the potent regulatory feedback loops, characteristic for the hypothalamus-pituitary-thyroid axis, TSH fluctuations may with great probability influence the immune effects of thyroid hormones observed in vivo. High level of TSH-receptor expression was found in murine DCs localized in spleen and lymph nodes. In vitro stimulation with TSH enhanced phagocytic activity of immature murine DCs, prolonged the initial state of phagocytosis and increased secretion of proinflammatory cytokines (IL- $1 \beta$ and IL-12) [111]. Moreover, an analysis of DC - TFC interactions in coculture revealed an existence of a complex crosstalk between these cellular compo- nents of the thyroid gland. The ability to survive in culture, proliferative activity and maturation of pig thyroid derived DCs depended strongly on humoral factors secreted by autologous TFCs stimulated with TSH - identified as GM-CSF and TGF- $\beta 1$ [112]. On the other hand, rat spleen derived DCs exerted an inhibitory action on TSH stimulated TFC growth and $\mathrm{T} 3$ secretion in coculture. Also in this case, cytokines (IL- $1 \beta$ and IL-6) seemed to play a role of crucial mediators [113]. However, there is still little knowledge of TSH receptor expression in main human leukocyte subsets and immune function of TSH in humans. In our clinical model, based on the thyroidectomised patients receiving systemically recombinant human (rh) TSH, we assessed conventional and plasmacytoid peripheral blood DCs under conditions independent from "natural" thyroid hormones fluctuations and found that systemic administration of rhTSH did not exert any significant effects neither on quantitative nor phenotypic parameters of the assessed DC subpopulations [114].

In the light of these in vitro and ex vivo observations we may assume that the DCs interactions with the humoral and cellular components of the pituitary-thyroid axis depend not only on the DC functional characteristics (DC subtype, stage of maturation, activation state) but are also influenced by multiple local, organ-specific, regulatory circuits. This suggestion seems to be further supported by the fact that murine DCs located in secondary lymphoid tissues were shown to produce and secrete TSH and in vitro studies confirmed DCs as the most potent known TSH producers in immune system. Interestingly, TSH production by DCs increased considerably in response to bacterial products $[115,116]$, suggesting possible role of DC associated auto- and paracrine TSH secretion in primary immune response.

\section{Conclusions}

An increasing evidence points at DCs as crucial players in autoimmune and malignant thyroid disorders. The wide engagement of DCs in virtually all phases of thyroid autoaggression and malignancy underlines the need of further research directed on characterization of the role of particular DC subpopulations in thyroid pathology. The recent findings suggest plasmacytoid DCs and their interaction with regulatory $T$ cells as particularly interesting. The DC associated local regulatory processes (including secretion of TSH and other mediators) represent another poorly understood issue of great importance for both thyroid physiological function and pathology. 


\section{References}

1. Savina A, Amigorena S. Phagocytosis and antigen presentation in dendritic cells. Immunol Rev. 2007;219:143-156.

2. Winzler C, Rovere P, Rescigno M et al. Maturation stages of mouse dendritic cells in growth factor-dependent long-term cultures. J Exp Med. 1997;185:317-328.

3. Sozzani S, Allavena P, Vecchi A, Mantovani A. Chemokines and dendritic cell traffic. J Clin Immunol. 2000;20:151-160.

4. Pletinckx K, Döhler A, Pavlovic V, Lutz MB. Role of dendritic cell maturity/costimulation for generation, homeostasis, and suppressive activity of regulatory T cells. Front Immunol. 2011;27:39.

5. Klatka J, Grywalska E, Wasiak M et al. The assessment of selected molecules belonging to B7 family on the mature dendritic cells in laryngeal cancer patients. Otolaryngol Pol. 2012;66:413-418.

6. Summers deLuca L, Gommerman JL. Fine-tuning of dendritic cell biology by the TNF superfamily. Nat Rev Immunol. 2012;12:339-351.

7. Vigouroux S, Yvon E, Wagner HJ et al. Induction of antigen-specific regulatory $\mathrm{T}$ cells following overexpression of a Notch ligand by human B lymphocytes. J Virol. 2003;77:1087210880.

8. Gopisetty A, Bhattacharya P, Haddad C et al. OX40L/Jagged1 Cosignaling by GM-CSF-Induced Bone Marrow-Derived Dendritic Cells Is Required for the Expansion of Functional Regulatory T Cells. J Immunol. 2013;190:5516-5525.

9. Munn DH, Sharma MD, Mellor AL. Ligation of B7-1/B7-2 by Human CD4+ T Cells Triggers Indoleamine 2,3-Dioxygenase Activity in Dendritic Cells. J Immunol. 2004;172:4100-4110.

10. Cella M, Sallusto F, Lanzavecchia A. Origin, maturation and antigen presenting function of dendritic cells. Curr Opin Immunol. 1997;9:10-16.

11. Stasiołek M. The role of selected immunoregulatory cell populations in autoimmune demyelination. Neuro Endocrinol Lett. 2011;32:25-33.

12. Oppmann B, Lesley R, Blom B et al. Novel p19 protein engages IL-12p40 to form a cytokine, IL-23, with biological activities similar as well as distinct from IL-12. Immunity. 2000;13:715-725.

13. Agrawal S, Gupta S, Agrawal A. Human dendritic cells activated via dectin-1 are efficient at priming Th17, cytotoxic CD8 T and B cell responses. PLoS One. 2010;18:e13418.

14. Rissoan MC, Soumelis V, Kadowaki N et al. Reciprocal control of Thelper cell and dendritic cell differentiation. Science. Feb 19, 1999:1183-1186.

15. Moseman EA, Liang X, Dawson AJ et al. Human plasmacytoid dendritic cells activated by $\mathrm{CpG}$ Oligodeoxynucleotides induce the generation of CD4+CD25+ regulatory T cells. $J$ Immunol. 2004;173:4433-4442.

16. Stasiołek M, Bayas A, Kruse N et al. Impaired maturation and altered regulatory function of plasmacytoid dendritic cells in multiple sclerosis. Brain. 2006;129:1293-1305.

17. Ito T, Yang M, Wang YH et al. Plasmacytoid dendritic cells prime IL-10-producing T regulatory cells by inducible costimulator ligand. J Exp Med. 2007;204:105-115.

18. Volkmann A, Zal T, Stockinger B. Antigen-presenting cells in the thymus that can negatively select MHC class II-restricted $\mathrm{T}$ cells recognizing a circulating self antigen. $J$ Immunol. 1997;158:693-706.

19. Yamazaki S, Iyoda $\mathrm{T}$, Tarbell $\mathrm{K}$ et al. Direct expansion of functional CD25+ CD4+ regulatory T cells by antigen-processing dendritic cells. J Exp Med. 2003;198:235-247.
20. Yamazaki S, Bonito AJ, Spisek R, Dhodapkar M, Inaba K, Steinman RM. Dendritic cells are specialized accessory cells along with TGF-beta for the differentiation of Foxp3+ CD4+ regulatory T cells from peripheral Foxp3 precursors. Blood. 2007;110:4293-4302.

21. Idoyaga J, Fiorese C, Zbytnuik L et al. Specialized role of migratory dendritic cells in peripheral tolerance induction. J Clin Invest. 2013;123:844-854.

22. Dzięgiel P, Dolińska-Krajewska B, Dumańska M et al. Coexpression of CD1a, langerin and Birbeck's granules in Langerhans cell histocytoses (LCH) in children: ultrastructural and immunocytochemical studies. Folia Histochem Cytobiol. 2007;45:21-25.

23. Croizet K, Rabillout R, Kostrouch Z, Nicolas JF, Rousset B. Culture of Dendritic Cells from a Nonlymphoid Organ, the Thyroid Gland: Evidence for TNF $\alpha$-Dependent Phenotypic Changes of Thyroid-Derived Dendritic Cells. Lab Invest. 2000;80:1215-1225.

24. Kabel PJ, Voorbij HA, De Haan M et al. Intrathyroidal dendritic cells. J Clin Endocrinol Metab. 1988;66:199-207.

25. Wilders-Truschnig MM, Kabel PJ, Drexhage $\mathrm{H}$ et al. Intrathyroidal dendritic cells, epitheloid cells, and giant cells in iodine deficient goiter. Am J Pathol. 1989;135:219-225.

26. Dimal P, Wilders-Truschnig MM, Leb G et al. Thyroid infiltrating dendritic cells, epitheloid cells and giant cells in iodine deficiency. Acta Med Austriaca. 1990;17:43.

27. Kabel PJ, Voorbij HA, van der Gaag RD et al. Dendritic cells in autoimmune thyroid disease. Acta Endocrinol Suppl (Copenh). 1987;281:42-48.

28. Voorby HA, Kabel PJ, de Haan M et al. Dendritic cells and class II MHC expression on thyrocytes during the autoimmune thyroid disease of the BB rat. Clin Immunol Immunopathol. 1990;55:9-22.

29. Many MC, Maniratunga S, Varis I, Dardenne M, Drexhage HA, Denef JF. Two-step development of Hashimoto-like thyroiditis in genetically autoimmune prone non-obese diabetic mice: effects of iodine-induced cell necrosis. J Endocrinol. 1995;147:311-320.

30. Knight SC, Farrant J, Chan J, Bryant A, Bedford PA, Bateman C. Induction of autoimmunity with dendritic cells: studies on thyroiditis in mice. Clin Immunol Immunopathol. 1988;48:277-289.

31. Watanabe H, Inaba M, Adachi Y et al. Experimental autoimmune thyroiditis induced by thyroglobulin-pulsed dendritic cells. Autoimmunity. 1999;31:273-282.

32. Li HS, Verginis P, Carayanniotis G. Maturation of dendritic cells by necrotic thyrocytes facilitates induction of experimental autoimmune thyroiditis, Clin Exp Immunol. 2006;144:467-474.

33. Verginis P, Li HS, Carayanniotis G. Tolerogenic Semimature Dendritic Cells Suppress Experimental Autoimmune Thyroiditis by Activation of Thyroglobulin-Specific CD4+CD25+ T Cells. J Immunol. 2005;174:7433-7439.

34. Vasu C, Dogan RNE, Holterman MJ, Prabhakar BS. Selective Induction of Dendritic Cells Using Granulocyte Macrophage-Colony Stimulating Factor, But Not fms-Like Tyrosine Kinase Receptor 3-Ligand, Activates Thyroglobulin-Specific $\mathrm{CD} 4^{+} / \mathrm{CD} 25^{+} \mathrm{T}$ Cells and Suppresses Experimental Autoimmune Thyroiditis. J Immunol. 2003;170:5511-5522.

35. Ganesh BB, Cheatem DM, Sheng JR, Vasu C, Prabhakar BS. GM-CSF-induced CD11 ${ }^{+} \mathrm{CD} 8 \mathrm{a}$ - dendritic cells facilitate Foxp $^{+}$and $\mathrm{IL}-10^{+}$regulatory $\mathrm{T}$ cell expansion resulting in suppression of autoimmune thyroiditis. Int Immunol. 2009;21:269-282. 
36. Gangi E, Vasu C, Cheatem D, Prabhakar BS. IL-10-Producing $\mathrm{CD} 4{ }^{+} \mathrm{CD} 25^{+}$Regulatory $\mathrm{T}$ Cells Play a Critical Role in Granulocyte-Macrophage Colony- timulating Factor-Induced Suppression of Experimental Autoimmune Thyroiditis. J Immonol. 2005;174:7006-7013.

37. Sakaguchi S. Naturally arising Foxp3-expressing CD25+CD4+ regulatory $\mathrm{T}$ cells in immunological tolerance to self and nonself. Nat Immunol. 2005;6:345-352.

38. Yamazaki S, Steinman RM. Dendritic cells as controllers of antigen-specific Foxp3+ regulatory T cells. J Dermatol Sci. 2009;54:69-75.

39. Bhattacharya P, Gopisetty A, Ganesh BB, Sheng JR, Prabhakar BS. GM-CSF-induced, bone-marrow-derived dendritic cells can expand natural Tregs and induce adaptive Tregs by different mechanisms. J Leukoc Biol. 2011;89:235-249.

40. Quadbeck B, Eckstein AK, Tews S et al. Maturation of thyroidal dendritic cells in Graves' disease. Scand. J Immunol. 2002;55:612-620.

41. Roura-Mir C, Catálfamo M, Cheng T et al. CD1a and CD1c Activate Intrathyroidal T Cells during Graves' Disease and Hashimoto's Thyroiditis. J Immunol. 2005;174:3773-3780.

42. Xu WC, Chen SR, Huang JX et al. Expression and distribution of S-100 protein, CD83 and apoptosis-related proteins (Fas, FasL and Bcl-2) in thyroid tissues of autoimmune thyroid diseases. Eur J Histochem. 2007;51:291-300.

43. Ruiz-Riol M, Barnils Mdel P, Colobran Oriol R et al. Analysis of the cumulative changes in Graves' disease thyroid glands points to IFN signature, plasmacytoid DCs and alternatively activated macrophages as chronicity determining factors. J Autoimmun. 2011;36:189-200.

44. Hammerstad SS, Jahnsen FL, Tauriainen S et al. Inflammation and increased myxovirus resistance protein A expression in thyroid tissue in the early stages of Hashimoto's thyroiditis. Thyroid. 2013;23:334-341.

45. Hammerstad SS, Jahnsen F, Tauriainen S et al. Immunological Changes and Increased Expression of Myxovirus Resistance Protein A in Thyroid Tissue of Patients with Recent Onset and Untreated Graves' Disease. Thyroid. 2014;24:537-544.

46. Mao C. Wang S, Xiao Y et al. Impairment of Regulatory Capacity of CD4+CD25+ Regulatory T Cells Mediated by Dendritic Cell Polarization and Hyperthyroidism in Graves' Disease. J Immunol. 2011;186:4734-4743.

47. Leskela S, Rodríguez-Muñoz A, de la Fuente $\mathrm{H}$ et al. Plasmacytoid dendritic cells in patients with autoimmune thyroid disease. J Clin Endocrin Metab. 2013;98:2822-2833.

48. Harden JL, Egilmez NK. Indoleamine 2,3-Dioxygenase and Dendritic Cell Tolerogenicity. Immunol. Invest. 2012;41:738764.

49. Matysiak M, Stasiołek M, Orłowski W et al. Stem cells ameliorate EAE via an indoleamine 2,3-dioxygenase (IDO) mechanism. J Neuroimmunol. 2008;193:12-23.

50. Nakamura Y. Watanabe M, Matsuzuka F, Maruoka H, Miyauchi A, Iwatani Y. Intrathyroidal $\mathrm{CD}^{+} \mathrm{T}$ Lymphocytes Express High Levels of Fas and $\mathrm{CD} 4{ }^{+} \mathrm{CD}^{+}$Macrophages/ Dendritic Cells Express Fas Ligand in Autoimmune Thyroid Disease. Thyroid. 2004;14:819-824.

51. Bossowski A, Czarnocka B, Stasiak-Barmuta A et al. Analiza ekspresji cząsteczek Fas, FasL oraz kaspazy 8 w tkance gruczołu tarczowego u młodych pacjentów z chorobami immunologicznymi i nieimmunologicznymi gruczołu tarczowego. Endokrynol Pol. 2007;58:303-313.

52. Lu H, Ouyang W, Huang C. Inflamation, a Key Event in Cancer Development. Mol Cancer Res. 2006;4:221-233.
53. Clemente CG, Mihm MC Jr, Bufalino R, Zurrida S, Collini $\mathrm{P}$, Cascinelli N. Prognostic value of tumour infiltrating lymphocytes in the vertical growth phase of primary cutaneous melanoma. Cancer. 1996;77:1303-1310.

54. Naito Y, Saito K, Shiiba K et al. CD8+ T cells infiltrated within cancer cell nests as a prognostic factor in human colorectal cancer. Cancer Res. 1998;58:3491-3494.

55. Zhang L, Conejo-Garcia JR, Katsaros D et al. Intratumoral $\mathrm{T}$ cells, recurrence and survival in epithelial ovarian cancer. N Engl J Med. 2003;348:203-213.

56. Mantovani A, Allavena P, Sozzani S, Vecchi A, Locati M, Sica A. Chemokines in the recruitment and shaping of the leukocyte infiltrate of tumors. Semin Cancer Biol. 2004;14:155-160.

57. Repplinger D, Bargren A, Zhang YW et al. Is Hashimoto's thyroiditis a risk factor for papillary thyroid cancer.J Surg Res. 2008;150:49-52.

58. Matesa-Anic D, Matesa N, Dabelic N, Kusic Z. Coexistence of papillary carcinoma and Hashimoto's thyroiditis. Acta Clin Croat. 2009;48:9-12.

59. Siriweera EH, Ratnatung NV. Profile of Hashimoto's thyroiditis in Sri Lankans: is there an increased risk of ancillary pathologies in Hashimoto's thyroiditis. J Thyroid Res. 2010; 2010:124264.

60. Mukasa K, Noh JY, Kunii Y et al. Prevalence of malignant tumors and adenomatous lesions detected by ultrasonographic screening in patients with autoimmune thyroid disease. Thyroid. 2011;21:37-41.

61. Cyniak-Magierska A, Wojciechowska-Durczyńska K, Krawczyk-Rusiecka K et al. Assessment of RET/PTC1 and RET/ PTC3 rearrangements in fine-needle aspiration biopsy specimens collected from patients with Hashimoto's thyroiditis. Thyroid Res. 2011;4:5.

62. Jankovic B, Le KT, Hershman JM. Hashimoto's Thyroiditis and Papillary Thyroid Carcinoma: Is there a Correlation. J Clin Endocrinol Metab. 2013;98:474-482.

63. Wirtschafter A, Schmidt R, Rosen D et al. Expression of the RET/PTC fusion gene as a marker for papillary carcinoma in Hashimoto's thyroiditis, Laryngoscope. 1997;107:95-100.

64. Rhoden KJ, Unger K, Salvatore G et al. RET/papillary thyroid cancer rearrangement in nonneoplastic thyrocytes: follicular cells of Hashimoto's thyroiditis share low-level recombination events with a subset of papillary carcinoma.J Clin Endocrinol Metab. 2006;91:2414-2423.

65. Russell JP, Engiles JB, Rothstein JL. Proinflammatory mediators and genetic background in oncogene mediated tumor progression. J Immunol. 2004;172:4059-4067.

66. Menetrier-Caux C, Montmain G, Dieu MC et al. Inhibition of the differentiation of dendritic cells from CD34(+) progenitors by tumor cells: role of interleukin- 6 and macrophage colony-stimulating factor. Blood. 1998;92:4778-4791.

67. Cunha LL, Marcello MA, Morari EC et al. Differentiated thyroid carcinomas may elude the immune system by B7H1 upregulation. Endocr Relat Cancer. 2013;20:103-110.

68. Yamakawa M, Yamada K, Orui H et al. Immunohistochemical analysis of dendritic/Langerhans cells in thyroid carcinomas. Anal Cell Pathol. 1995;8:331-343.

69. Scarpino S, Stoppacciaro A, Ballerini F et al. Papillary carcinoma of the thyroid: hepatocyte growth factor (HGF) stimulates tumor cells to release chemokines active in recuiting dendritic cells. Am J Pathol. 2000;156:831-837.

70. Giannice R, Erreni M, Allavena P et al. Chemokines mRNA expression in relation to the Macrophage Migration Inhibitory Factor (MIF) mRNA and Vascular Endothelial Growth Factor (VEGF) mRNA expression in the microenvironment 
of endometrial cancer tissue and normal endometrium: a pilot study. Cytokine. 2013;64:509-515.

71. Osterbur J, Sprague L, Muccioli M et al. Adhesion to substrates induces dendritic cell endothelization and decreases immunological response. Immunobiology. 2013;218:64-75.

72. Curiel TJ, Cheng P, Mottram P et al. Dendritic cell subsets differentially regulate angiogenesis in human ovarian cancer. Cancer Res. 200;64:5535-5538.

73. Wyckoff J, Wang W, Lin EY et al. A paracrine loop between tumor cells and macrophages is required for tumor cell migration in mammary tumors. Cancer Res. 2004;64:7022-7029.

74. Ning $\mathrm{H}$, Shao QQ, Ding KJ et al. Tumor-infiltrating regulatory T cells are positively correlated with angiogenic status in renal cell carcinoma. Chin Med J (Engl). 2012;125:2120-2125.

75. Scarlett UK, Rutkowski MR, Rauwerdink AM et al. Ovarian cancer progression is controlled by phenotypic changes in dendritic cells. J Exp Med. 2012;209:495-506.

76. Zhou Z, Li W, Song Y et al. Growth differentiation factor-15 suppresses maturation and function of dendritic cells and inhibits tumor-specificimmune response. PLoS One. 2013;8:e78618

77. Facciabene A, Peng X, Hagemann IS et al. Tumour hypoxia promotes tolerance and angiogenesis via CCL28 and T(reg) cells. Nature. 2011;475:226-230.

78. Conrad C, Gilliet M. Plasmacytoid dendritic cells and regulatory $\mathrm{T}$ cells in the tumor microenvironment: A dangerous liaison. Oncoimmunology. 2013;2:e23887.

79. Liu C, Yu S, Kappes J et al. Expansion of spleen myeloid suppressor cells represses NK cell cytotoxicity in tumor-bearing host. Blood. 2007;109:4336-4342.

80. Ohki S, Shibata M, Gonda K et al. Circulating myeloid-derived suppressor cells are increased and correlate to immune suppression, inflammation and hypoproteinemia in patients with cancer. Oncol Rep. 2012;28:453-458.

81. Cunha LL, Morari EC, Guihen ACT et al. Infiltration of a mixture of immune cells may be related to good prognosis in patients with differentiated thyroid carcinoma. Clin Endocrinol. 2012;77:918-925.

82. Cunha LL, Morari EC, Guihen ACT et al. Infiltration of a mixture of different immune cells may be related to molecular profile of differentiated thyroid cancer. Endocr Relat Cancer. 2012;19:L31-L36.

83. Marcello MA, Morari EC, Cunha LL et al. P53 and expression of immunological markers may identify early stage thyroid tumors. Clin Dev Immunol. 2013;2013:846584.

84. Schröder S, Schwarz W, Rehpenning W et al. Dendritic/ Langerhans cells and prognosis in patients with papillary thyroid carcinomas. Immunocytochemical study of 106 thyroid neoplasms correlated to follow-up data. Am J Clin Pathol. 1988;89:295-300.

85. Yamakawa M, Kato H, Takagi S et al. Dendritic cells in various human thyroid diseases. In Vivo. 1993;7:249-256.

86. Tsuge K, Takeda H, Kawada S, Maeda K, Yamakawa M. Characterization of dendritic cells in differentiated thyroid cancer. J Pathol. 2005;205:565-576.

87. Batistatou A, Zolota V, Scopa CD. S- 100 protein + dendritic cells and CD34+ dendritic interstitial cells in thyroid lesions. Endocr Pathol. 2002;13:111-115.

88. Ugolini C, Basolo F, Proietti A. Lymphocyte and immature dendritic cell infiltrates in differentiated, poorly differentiated, and undifferentiated thyroid carcinoma. Thyroid. 2007;17:389-393.

89. Xu WC, Li X, Chen SR et al. Expression and distribution of S-100, CD83 and apoptosis-related proteins (Fas, FasL and Bcl-2) in tissues of thyroid carcinoma. Eur J Histochem. 2008;52:153-162.

90. $\mathrm{Xu}$ WC, Li ZB, Chen YR et al. Expression and distribution of S-100, CD83, and costimulatory molecules (CD80 and CD86) in tissues of thyroid papillary carcinoma. Cancer Invest. 2011;29:286-292.

91. Proietti A, Ugolini C, Melillo RM et al. Higher intratumoral expression of CD1a, tryptase, and CD68 in a follicular variant of papillary thyroid carcinoma compared to adenomas: correlation with clinical and pathological parameters. Thyroid. 2011;21:1209-1215.

92. Pusztaszeri M, Shadow P, Faquin W. Association of CD1a-positive dendritic cells with papillary thyroid carcinoma in thyroid fine-needle aspirations. Cancer Cytopathol. 2013;121:206-213.

93. Thompson LD, Wieneke JA, Heffess CS. Diffuse sclerosing variant of papillary thyroid carcinoma: a clinicopathologic and immunophenotypic analysis of 22 cases. Endocr Pathol. 2005;16:331-348.

94. Hirokawa M, Kuma S, Miyauchi A et al. Morules in cribriform-morular variant of papillary thyroid carcinoma: Immunochistochemical characteristics and distinction from squamous metaplasia. APMIS. 2004;112:275-282.

95. Valladeau J, Ravel O, Dezutter-Dambuyant C et al. Langerin, a novel C-type lectin specific to Langerhans cells, is an endocytic receptor that induces the formation of Birbeck granules. Immunity. 2000;12:71-81.

96. Bell D, Chomarat P, Broyles D et al. In breast carcinoma tissue, immature dendritic cells reside within the tumor, whereas mature dendritic cells are located in peritumoral areas. J Exp Med. 1999;190:1417-1426.

97. Furihata M, Ono Y, Ichikawa K, Tomita S, Fujimori T, Kubota K. Prognostic significance of CD83 positive, mature dendritic cells in the gallbladder carcinoma. Oncol Rep. 2005; 14:353-356.

98. Ladányi A, Kiss J, Somlai B et al. Density of DC-LAMP(+) mature dendritic cells in combination with activated $\mathrm{T}$ lymphocytes infiltrating primary cutaneous melanoma is a strong independent prognostic factor. Cancer Immunol Immunother. 2007;56:1459-1469.

99. Hilly O, Koren R, Raz R et al. The role of S100-positive dendritic cells in the prognosis of papillary thyroid carcinoma. Am J Clin Pathol. 2013;139:87-92.

100. Yu H, Huang X, Liu X et al. Regulatory T cells and plasmacytoid dendritic cells contribute to the immune escape of papillary thyroid cancer coexisting with multinodular non-toxic goiter. Endocrine. 2013;44:172-181.

101. Papewalis C, Wuttke M, Seissler J et al. Dendritic cell vaccination with xenogenic polypeptide hormone induces tumor rejection in neuroendocrine cancer. Clin Cancer Res. 2008;14:4298-4305.

102. Schott M, Seissler J, Lettmann M et al. Immunotherapy for medullary thyroid carcinoma by dendritic cell vaccination. J Clin Endocrinol Metab. 2001;86:4965-4969.

103. Stift A, Sachet M, Yagubian R et al. Dendritic cell vaccination in medullary thyroid carcinoma. Clin Cancer Res. 2004;10:2944-2953.

104. Bachleitner-Hofmann T, Stift A, Friedl J et al. Stimulation of autologous antitumor t-cell responses against medullary thyroid carcinoma using tumor lysate-pulsed dendritic cells. J Clin Endocrinol Metab. 2002;87:1098-1104.

105. Bachleitner-Hofmann T, Friedl J, Hassler M et al. Pilot trial of autologous dendritic cells loaded with tumor lysate(s) from allogeneic tumor cell lines in patients with 
metastatic medullary thyroid carcinoma. Oncol Rep. 2009;21:1585-1592.

106. Kuwabara K. Namashita N, Morishita M et al. Results of a phase I clinical study using dendritic cell vaccinations for thyroid cancer. Thyroid. 2007;17:53-58.

107. Mascanfroni ID, del Mar Montesinos M, Susperreguy N et al. Control of dendritic cell maturation and function by triiodothyronine. FASEB J. 2008;22:1032-1042.

108. Montesinos MM, Alamino VA, Mascanfroni ID et al. Dexamethasone counteracts the immunostimulatory effects of triiodothyronine (T3) on dendritic cells. Steroids. 2012;77: $67-76$.

109. Mascanfroni ID, del Mar Montesinos M, Alamino VA et al. Nuclear Factor (NF)- $\kappa$ B-dependent thyroid hormone receptor $\beta_{1}$ expression controls dendritic cell function via Akt Signaling. J Biol Chem. 2010;285:9569-9582.

110. Dedecjus M, Stasiołek M, Brzeziński J et al. Thyroid Hormones Influence Human Dendritic Cells' Phenotype, Function, and Subsets Distribution. Thyroid. 2011;21:533-540.

111. Bagriacik EU, Klein JR. The Thyrotropin (thyroid-stimulating hormone) receptor is expressed on murine dendritic cells and on a subset of $\mathrm{CD} 45 \mathrm{RB}^{\text {high }}$ lymph node $\mathrm{T}$ cells: functional role for thyroid-stimulating hormone during immune activation. J Immunol. 2000;164:6158-6165.

112. Croizet K, Trouttet-Masson S, Rabilloud R et al. Signaling from epithelial to dendritic cells of the thyroid gland: evidence for thyrocyte-derived factors controlling the survival, multiplication and endocytic activity of dendritic cells. Lab Invest. 2001;81:1601-1613.

113. Simons PJ, Delemarre FGA, Drexhage HA. Antigen-presenting dendritic cells as regulators of the growth of thyrocytes: a role of interleukin-1 $\beta$ and interleukin-6. Endocrinology. 1998;139:3148-3156.

114. Stasiołek M, Adamczewski Z, Puła B et al. Distribution of subpopulations of dendritic cells in peripheral blood of patients treated with exogenous thyrotropin. Thyroid Res. 2012;5:18.

115. Bagriacik EU, Klein JR. Rapid and transient reduction in circulating thyroid hormones following systemic antigen priming: Implications for functional collaboration between dendritic cells and thyroid. Cell Immunol. 2001;212:92-100.

116. Klein JR. The Immune system as a regulator of thyroid hormone Activity. Exp Biol Med. 2006;231:229-236.

Submitted: 3 January, 2014 Accepted after reviews: 10 March, 2014 